\title{
Construction and analysis of dynamic solidification curves for non-equilibrium solidification process in lost-foam casting hypo- eutectic gray cast iron
}

\author{
* Ming-guo Xie and Chang-an Zhu \\ School of Engineering Science, University of Science and Technology of China, Hefei 230026, China
}

\begin{abstract}
Most lost-foam casting processes involve non-equilibrium solidification dominated by kinetic factors, while construction of a common dynamic solidification curve is based on pure thermodynamics, not applicable for analyses and research of non-equilibrium macro-solidification processes, and the construction mode can not be applied to nonequilibrium solidification process. In this study, the construction of the dynamic solidification curve (DSC) for the nonequilibrium macro-solidification process included: a modified method to determine the start temperature of primary austenite precipitation $\left(T_{\mathrm{AL}}\right)$ and the start temperature of eutectic solidification ( $T_{\mathrm{ES}}$ ); double curves method to determine the temperature of the dendrite coherency point of primary austenite $\left(\boldsymbol{T}_{\mathrm{AC}}\right)$ and the temperature of eutectic cells collision point ( $\left.\boldsymbol{T}_{\mathrm{EC}}\right)$; the "technical solidus" method to determine the end temperature of eutectic reaction $\left(\boldsymbol{T}_{\mathrm{EN}}\right)$. For this purpose, a comparative testing of the non-equilibrium solidification temperature fields in lost-foam casting and green sand mold casting hypoeutectic gray iron was carried out. The thermal analysis results were used to construct the DSCs of both these casting methods under non-equilibrium solidification conditions. The results show that the transformation rate of non-equilibrium solidification in hypoeutectic gray cast iron is greater than that of equilibrium solidification. The eutectic solidification region presents a typical mushy solidification mode. The results also indicate that the primary austenite precipitation zone of lost-foam casting is slightly larger than that of green sand casting. At the same time, the solid fraction $\left(f_{s}\right)$ of the dendrite coherency points in lost-foam casting is greater than that in the green sand casting. Therefore, from these two points, lost-foam casting is more preferable for reduction of shrinkage and mechanical burntin sand tendency of the hypoeutectic gray cast iron. Due to the fact that the solidification process (from the surface to center) at primary austenite growth area in the lost-foam cylinder sample lags behind that in the green sand casting, the mushy solidification tendency of lost-foam casting is greater and the solidification time is longer.
\end{abstract}

Key words: hypo-eutectic gray cast iron; lost-foam casting; non-equilibrium solidification process; dynamic solidification curve

CLC numbers: TG251 Document code: A Article ID: 1672-6421(2017)03-176-08

$\mathrm{P}$ ioneer studies of the dynamic solidification curve (DSC) of castings date back to the late 1940s, when Ruddle from the British Institute of Metals measured the temperature field to analyze the solidification process of nonferrous alloy castings ${ }^{[1]}$. R. P. Dunphy et al from the Naval Research Laboratory in US ${ }^{[2]}$ constructed the DSC of hypoeutectic gray cast iron based on thermodynamics. The changes of the liquidus temperature, eutectic temperature, and the solidus temperature of the castings

\section{*Ming-guo Xie}

Male, 1965, M.E., Senior Engineer. Research area: cast alloys, lost-foam foundry process.

E-mail: xiemingguo@sina.com

Received: 2017-02-16; Accepted: 2017-04-01 were used to describe the corresponding solidification process. So far, the DSC is widely adopted in studies of the characteristics of the macro-solidification process of cast iron, especially in the analysis of the difference between solidification and process characteristics of ductile cast iron and gray cast iron ${ }^{[3]}$. Some researchers used the DSC in the near-equilibrium solidification process to construct the DSC of a nonequilibrium solidification process of cast iron ${ }^{[4,5]}$, but the temperature field and solidification characteristics of non-equilibrium solidification process are different from that of the near-equilibrium solidification process, so it is not appropriate to use the DSC of the near-equilibrium solidification process to explain non-equilibrium solidification process. Since the shape of the cooling 
curves in a non-equilibrium solidification process is mainly controlled by dynamic factors, the exact position of each critical point on the cooling curves cannot be accurately acquired based on such factors of thermodynamics as liquidus temperature, eutectic temperature, and "technical solidus temperature". Therefore, they cannot reflect the actual solidification process. P. Svidró, et al. ${ }^{[6]}$ analyzed the characteristic points of the cooling curves to study the macro-solidification process of hypoeutectic gray cast iron. However, due to the small sample size (30 $\mathrm{mm}$ in diameter) and other experimental drawbacks, they failed to improve the data accuracy and construct the corresponding DSC.

In this study, a new method was proposed to construct the DSC of hypoeutectic gray iron in a non-equilibrium solidification process. The macro-solidification process of the hypoeutectic gray cast iron in lost-foam casting under the nonequilibrium solidification condition was investigated. The results obtained contribute to the understanding of the microstructural transformation characteristics and help to improve the quality of lost-foam castings.

\section{Experimental procedures}

\subsection{Sample design}

The cylinder-shaped samples with dimensions of $\Phi 100 \times 300 \mathrm{~mm}$ (modulus $\mathrm{M}=25 \mathrm{~mm}$ ) were used in order to collect the temperature data for construction of DSC. The temperature point interval in the radial direction was $10 \mathrm{~mm}$ uniform distribution (Fig .1).



(a)

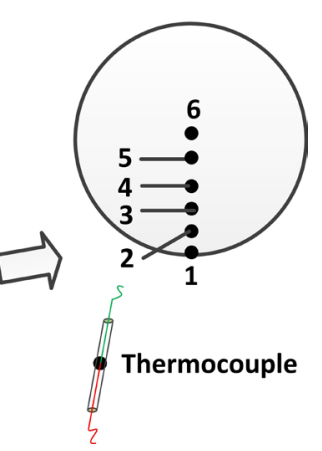

(b)
Fig. 1: Temperature measurement model (a) and location of temperature measuring points (b)

\subsection{Design of temperature measurement system}

The temperature field data was acquired by six thermocouples which were evenly mounted in the middle of the sample (Fig. 1). The special S-type thermocouple $(0.5 \mathrm{~mm}$ in diameter) was selected as the temperature detector, with a high-quality quartz protecting tube at an inner diameter of $1 \mathrm{~mm}$ and a wall thickness of $1 \mathrm{~mm}$. The thermocouples were processed to obtain close contact with the welding joints to minimize the thermal inertia during the temperature measurement. A NI Compact DAQ system was used to collect and process the temperature data. Figure 2 presents the actual casting process data acquisition system.

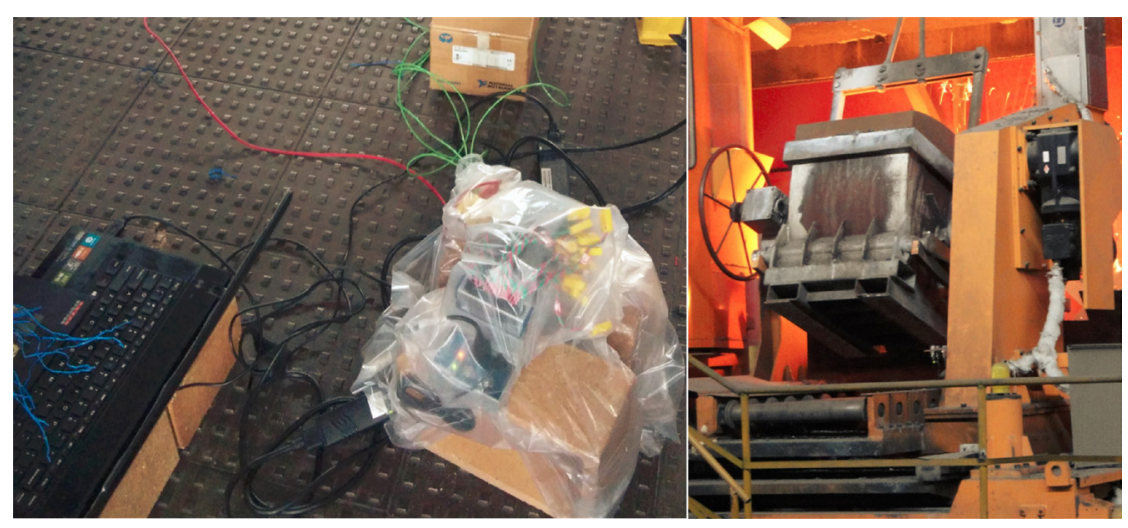

Fig. 2: Actual casting process data acquisition system

\subsection{Materials and casting process}

In this study, a comparative testing was performed by lost-foam and green sand casting HT250 hypoeutectic gray iron. The molten cast iron was inoculated with 75 Fe-Si. Figure 3 shows the casting molding test setup with temperature measurement.

The HT250 cast iron was melted in a 3 -ton conversion induction furnace fabricated by ABP GmbH. Spectro directreading spectrometer, carbon and sulfur analyzer, and thermal analyzer were used to analyze the chemical composition of molten metal, which is described in Table 1. The plug-in rapid thermocouple was applied to detect and control molten metal initial and pouring temperatures. The pouring temperatures for both casting methods were controlled for $1,430 \pm 15{ }^{\circ} \mathrm{C}$. The vacuum degree of lost-foam was kept at $-50 \pm 5 \mathrm{kPa}$.

Table 1: Chemical composition of HT250 molten iron (wt.\%)

\begin{tabular}{|cccccc} 
& C & Si & Mn & P & S \\
Before inoculation & 3.2 & 1.4 & 0.83 & $\leqslant 0.04$ & $\leqslant 0.04$ \\
After inoculation & 3.2 & 1.7 & 0.83 & $\leqslant 0.04$ & $\leqslant 0.04$
\end{tabular}



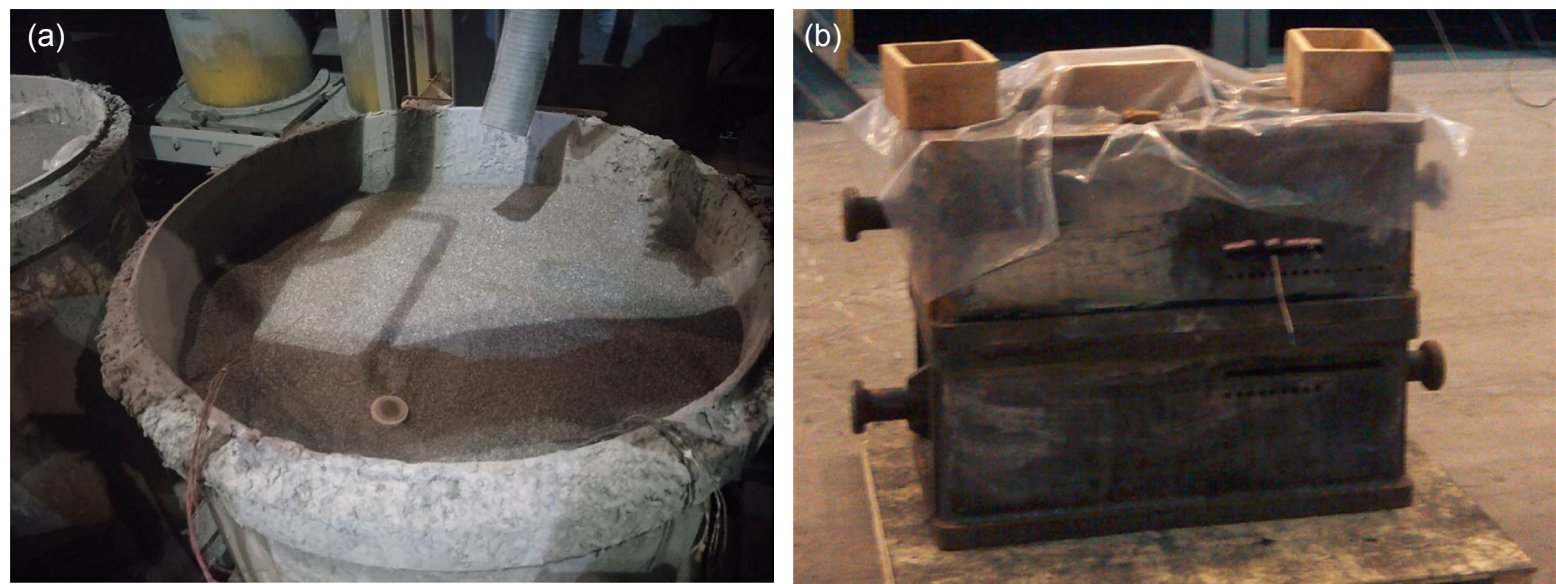

Fig. 3: Test moulds with temperature measurement

\section{Construction of DSC of non- equilibrium solidification process}

The cooling curves of lost foam and green sand casting hypoeutectic HT250 cast iron during solidification for each temperature measuring point with time were plotted in Figs. 4 and 5 .

Based on the cooling curves shown in Figs. 4 and 5, the DSC of non-equilibrium solidification process of hypoeutectic HT250

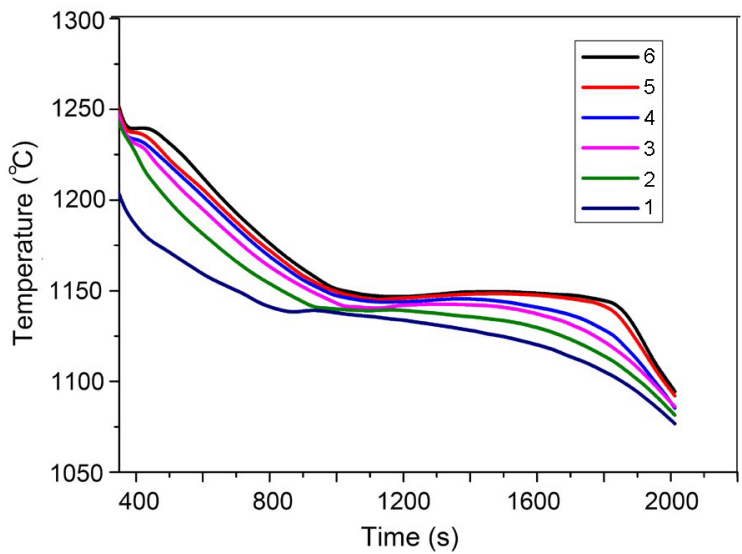

Fig. 4: Cooling curves for lost-foam casting

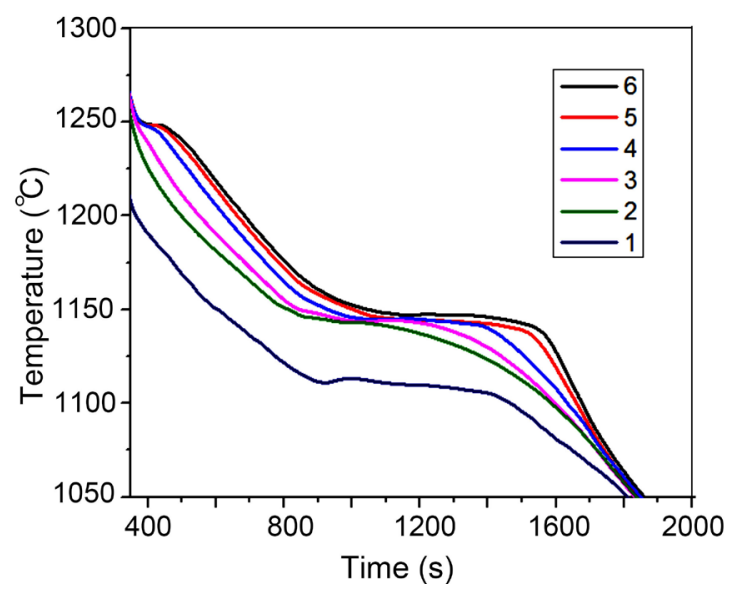

Fig. 5: Cooling curves for green sand casting cast iron was determined. The DSC was composed of four segments of interfacial wave curves: the beginning of primary austenite precipitation — the beginning of primary austenite dendritic maturation growth — the initiation of eutectic reaction — the ending of solidification. The second wave curve was rarely investigated in similar studies. In previous studies, the dendritic coherency phenomenon of critical point for transition from the primary austenite precipitation stagnation zone to the precipitation cooling zone on the cooling curve and relevant solidification mechanism have not been reasonably explained ${ }^{[7-8]}$. The prediction of this wave curve is positive to the analysis of the problems encountered in the process of casting solidification.

The characteristics points on the interfacial wave curves during solidification involve: starting point of the primary austenite precipitation $\left(t_{\mathrm{AL}}, T_{\mathrm{AL}}\right)$, starting point of austenite dendrite maturation growth $\left(t_{\mathrm{AC}}, T_{\mathrm{AC}}\right)$, starting point of eutectic solidification $\left(t_{\mathrm{ES}}, T_{\mathrm{ES}}\right)$ and ending point of eutectic solidification $\left(t_{\mathrm{EN}}, T_{\mathrm{EN}}\right)$. Figure 6 and Table 2 show the identification and definition of each characteristic point on the cooling curve ${ }^{[9-10]}$.

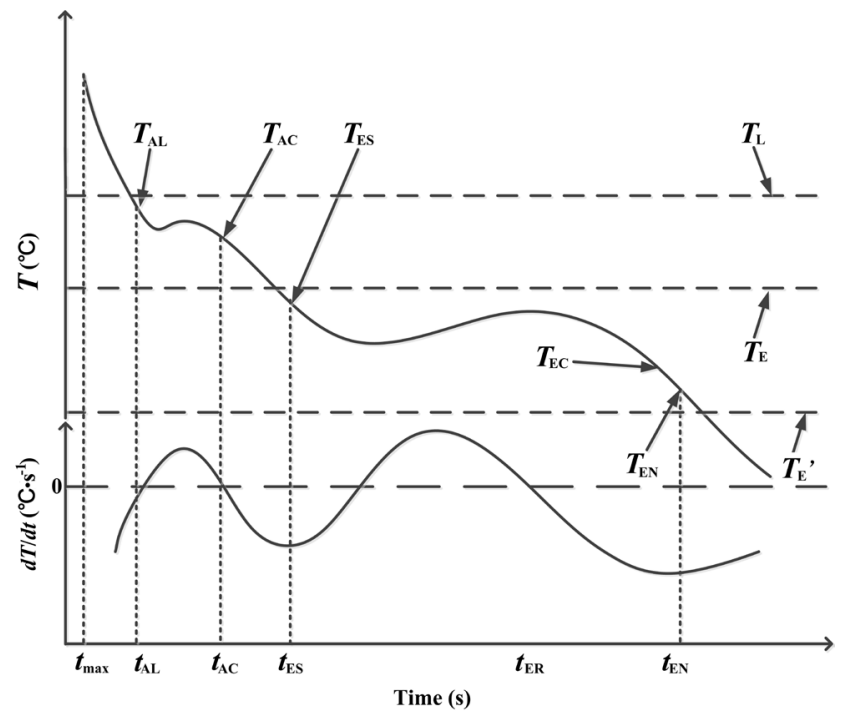

Fig. 6: Identification of characteristic points on cooling curve during solidification 
Table 2: Definition of characteristic points on cooling curve

\begin{tabular}{|c|c|c|c|}
\hline Designation & Definition & Designation & Definition \\
\hline$T / \mathrm{t}$ & Cooling cove in solidification process & $d T / d t$ & First derivative of the cooling curve \\
\hline$T_{\mathrm{E}}, T_{\mathrm{E}^{\prime}}$ & $\begin{array}{l}\text { Equilibrium temperatures of eutectic reaction of stable and } \\
\text { metastable molten iron }\left({ }^{\circ} \mathrm{C}\right)\end{array}$ & $T_{\mathrm{L}}$ & Molten iron liquidus temperature $\left({ }^{\circ} \mathrm{C}\right)$ \\
\hline$T_{\mathrm{AL}}$ & Start temperature of primary austenite precipitation $\left({ }^{\circ} \mathrm{C}\right)$ & $t_{\mathrm{AL}}$ & Start time of primary austenite precipitation (s) \\
\hline$T_{\mathrm{AC}}$ & Temperature of dendrite coherency point of primary austenite $\left({ }^{\circ} \mathrm{C}\right)$ & $t_{\mathrm{AC}}$ & $\begin{array}{l}\text { Start time of dendrite coherency point of primary } \\
\text { austenite }(s)\end{array}$ \\
\hline$T_{\mathrm{ES}}$ & Start temperature of molten iron eutectic reaction $\left({ }^{\circ} \mathrm{C}\right)$ & $t_{\mathrm{ES}}$ & Start time of molten iron eutectic reaction (s) \\
\hline$T_{\mathrm{EN}}$ & End temperature of molten iron eutectic reaction $\left({ }^{\circ} \mathrm{C}\right)$ & $t_{\mathrm{EN}}$ & End time of molten iron eutectic reaction (s) \\
\hline$T_{\mathrm{EC}}$ & Temperature of eutectic cells collision point $\left({ }^{\circ} \mathrm{C}\right)$ & $t_{\mathrm{EC}}$ & Start time of eutectic cells collision (s) \\
\hline
\end{tabular}

\subsection{Acquisition of characteristic points}

(1) The first order derivative of the cooling curve is taken to obtain the $T_{\mathrm{AL}}, T_{\mathrm{ES}}$ and $T_{\mathrm{EN}}$ values on the cooling curve and corresponding time as accurately as possible.

(2) The double-thermocouple technique was used to obtain the $T_{\mathrm{AC}}$ and $T_{\mathrm{EC}}$ values on the cooling curve and the corresponding time of the internal temperature measuring point.

\subsection{Modified method of $T_{\mathrm{AC}}$ and $T_{\mathrm{EC}}$}

The modified method of $T_{\mathrm{AC}}$ and $T_{\mathrm{EC}}$ is schematically presented in Fig. 7. Dendrite coherency point of primary austenite was determined by the change of

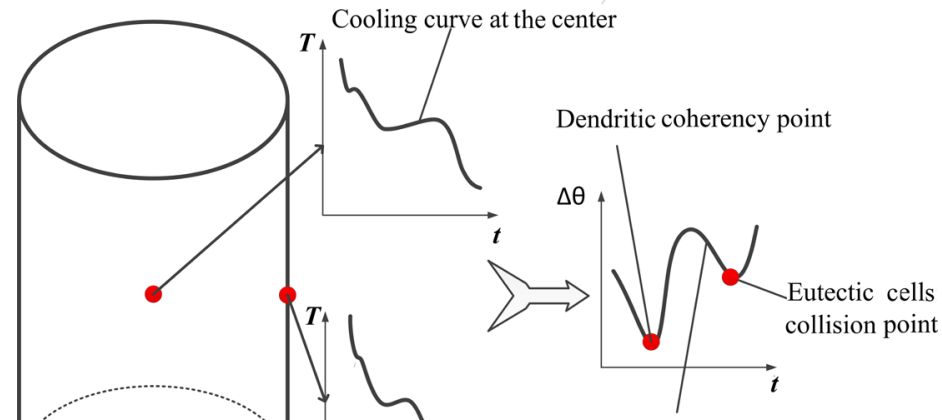

Cylinder sample

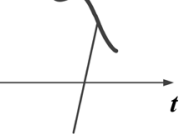

Temperature difference $\Delta \theta$ curve heat conductivity between structures at the boundary and the center. Once the dendrite coherency point was created, the heat transfer rate between the boundary and the center is speeded up, therefore, the temperature difference $\Delta \theta$ curve at the boundary and the center with time can be obtained. Thus, the dendrite coherency point and its temperature could be determined.

\subsection{Modified method of $T_{\mathrm{AL}}$ and $T_{\mathrm{ES}}$}

Due to the diversity of the cooling curve's shape during non-equilibrium solidification and the random disturbance of dynamic factors, there are some uncertainties in the first derivative curve when using the lowest value method ${ }^{[9,10]}$ to determine the $T_{\mathrm{AL}}$ and $T_{\mathrm{ES}}$. Therefore, it is necessary to correct the preliminary $T_{\mathrm{AL}}$ and $T_{\mathrm{ES}}$ data. According to the nonequilibrium solidification dynamical theory, the $T_{\mathrm{AL}}$ and $T_{\mathrm{ES}}$ values obtained by the same molten iron under different cooling rates should be linear with the square root of its cooling rate ${ }^{[11]}$ :

$$
\begin{aligned}
& T_{\mathrm{AL}}=T_{\mathrm{L}}-\mathrm{a}_{1}(d T / d t)^{1 / 2} \\
& T_{\mathrm{ES}}=T_{\mathrm{E}}-\mathrm{a}_{2}(d T / d t)^{1 / 2}
\end{aligned}
$$

where $\mathrm{a}_{1}$ and $\mathrm{a}_{2}$ are non-negative constants.

Accordingly, the following steps should be followed:

(1) Combined with the chemical composition of HT250 and CE in Table 3, the value of $T_{\mathrm{L}}$ is calculated by the interpolation

Cooling curve at the boundary

Fig. 7: Schematic diagram of dendrite coherency points measured by $\Phi 100 \mathrm{~mm} \times 300 \mathrm{~mm}$ cylinder sample

method; and then the stable state eutectic equilibrium $T_{\mathrm{E}}$ can be derived via Eq. (3) ${ }^{[13]}$ :

$$
T_{\mathrm{E}}=1154^{\circ} \mathrm{C}+4 \mathrm{wt} . \%(\mathrm{Si})-2 \mathrm{wt} . \%(\mathrm{Mn})-30 \mathrm{wt} . \%(\mathrm{P})
$$

(2) According to the intersection derivatives of $T_{\mathrm{L}}$ and $T_{\mathrm{E}}$ and each cooling curve, $d T / d t$ at the equilibrium solidification temperature for each measuring point is determined.

(3) Then, the preliminary obtained $T_{\mathrm{AL}}, T_{\mathrm{ES}}, T_{\mathrm{L}}, T_{\mathrm{E}}$, and $d T / d t$ values are substituted into Eq. (1) and (2), respectively, thus the average values of $a_{1}$ and $a_{2}$ are obtained for each point, as shown in Fig. 8.

(4) The average values of $a_{1}$ and $a_{2}$ are substituted into Eq. (1) and (2), the curves of $T_{\mathrm{AL}}$ and $T_{\mathrm{ES}}$ versus $d T / d t$ are obtained (Fig. 9). According to these two equations, the corrected values of $T_{\mathrm{AL}}$ and $T_{\mathrm{ES}}$ at each measuring point can be obtained. The corresponding $t_{\mathrm{AL}}$ and $t_{\mathrm{ES}}$ values for the determination of the DSC are obtained via the corrected values of $T_{\mathrm{AL}}$ and $T_{\mathrm{ES}}$.

Table 3: Variation of $T_{\llcorner}$with carbon equivalent ${ }^{[16]}$

\begin{tabular}{|cccccccc|} 
CE (\%) & 2.5 & 3.0 & 3.25 & 3.5 & 3.75 & 4.0 & 4.26 \\
\hline$T_{L}\left({ }^{\circ} \mathrm{C}\right)$ & 1336 & 1289 & 1263 & 1235 & 1212 & 1176 & 1153 \\
\multicolumn{5}{c}{ Note. CE $(\%)=w t . \%(C)+0.25 \mathrm{wt} . \%(\mathrm{Si})+$} & $0.5 \mathrm{wt}$. & $\%(\mathrm{P})$
\end{tabular}




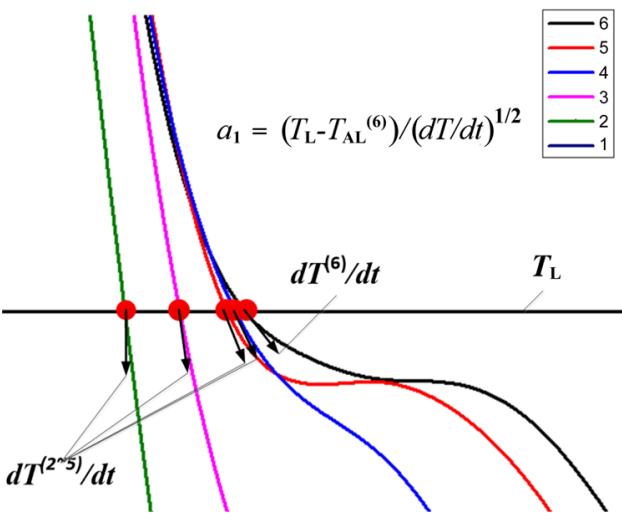

(a) Computation of $\mathrm{a}_{1}$

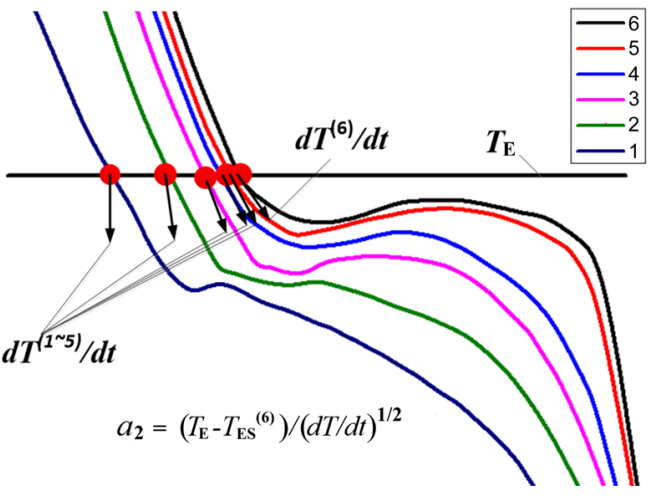

(b) Computation of $\mathrm{a}_{2}$

Fig. 8: Method of computing $a_{1}(a)$ and $a_{2}(b)$ at each measuring point
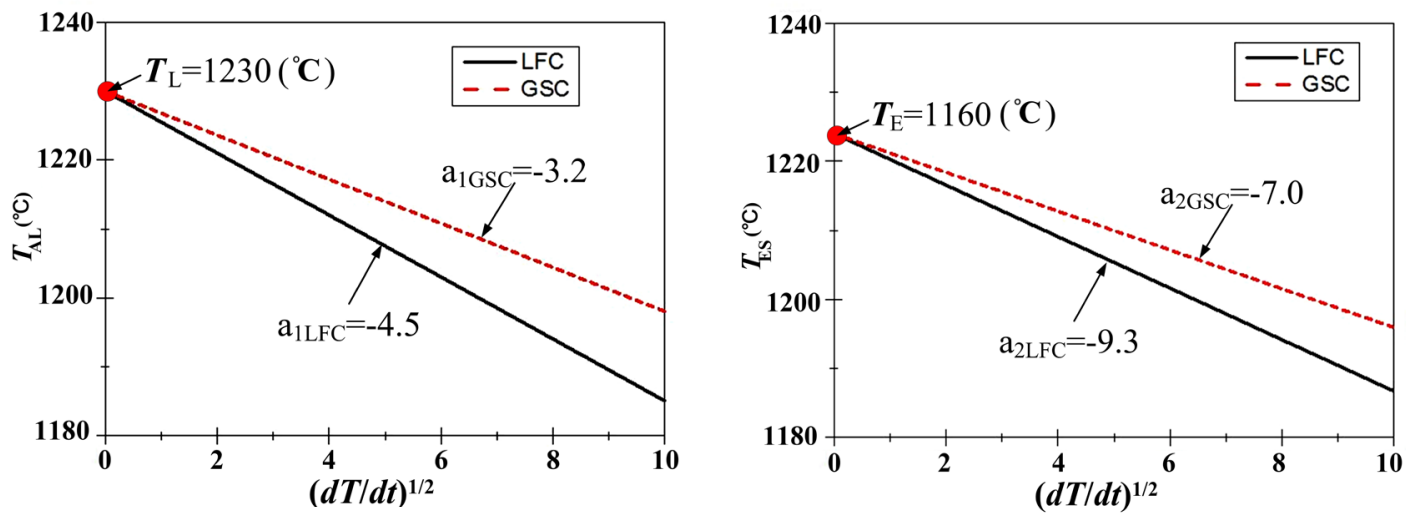

Fig. 9: Calculated results of modified line based on regression method

\subsection{Modified method of $T_{\mathrm{EN}}$}

The determination of true temperature at the end of the eutectic solidification of hypoeutectic gray cast iron has been a difficult problem in the cooling curve analysis ${ }^{[14]}$. Due to the fact that at the end of the solidification, there exists the segregation at the LTF (Last To Freeze) zone that is constituted by the small amount of residual melt existing among eutectic cells and accumulates many low melting point impurities, which reduce the solidification temperature. The degree of reduction is different with the composition, state, and cooling rate of segregation, which interfere with the analysis of the real temperature of the solidification, and makes the measured data scattered. Therefore, it is not to be used during the construction of the DSCs. If this interference occurring at the end of the solidification is ignored, and the $t_{\mathrm{EN}}$ is substituted by $t_{\mathrm{EC}}$ at the moment of eutectic cells' collision with each other, deviation between the $t_{\mathrm{EC}}$ and true solidification end time is relatively small, which is an acceptable system deviation. Therefore, this should be a reasonable substitution method. In the test, it was found that the $t_{\mathrm{EC}}$ at the moment of eutectic cells' collision with each other can be achieved using the same principle and method in the later period of eutectic solidification when determining the dendrite coherency points of the double cooling curves. Therefore, we selected the $t_{\mathrm{EC}}$ at the center as reference point substituting the $t_{\mathrm{EN}}$, set the $T_{\mathrm{A}}=T_{\mathrm{ES}}-T_{\mathrm{EC}}$ at the point to be "technical solidus temperature" range of molten iron eutectic solidification (Fig. 10), and it is hypothesized that there are equal values on the cooling curves of six measuring points, and their positions change with $T_{\mathrm{ES}}$ at the same speed. Thus, except for the temperature Point 6 on the sample surface, the corrected values of the $T_{\mathrm{EN}}$ on the cooling curves for temperature Points 1-5 and corresponding $t_{\mathrm{EN}}$ values can be obtained. Thereafter, $t_{\mathrm{E}}$ can also be achieved. The corrected values are shown in Table 4 .

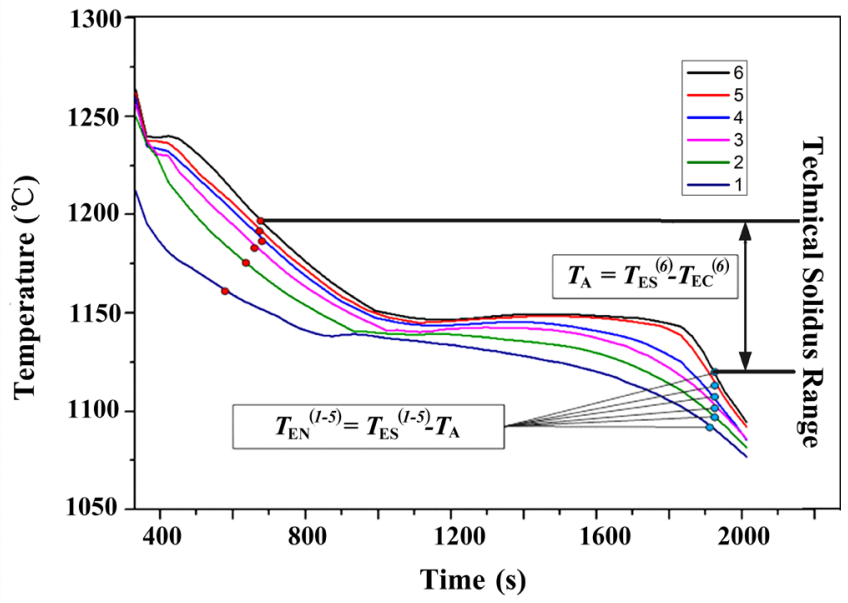

Fig. 10: Modified method diagram of $T_{\mathrm{EN}}$ 
Table 4: Corrected values of characteristic points

\begin{tabular}{|c|c|c|c|c|c|c|c|c|c|c|c|c|c|c|c|c|}
\hline \multirow{2}{*}{$\begin{array}{l}\text { Measuring } \\
\text { points }\end{array}$} & \multicolumn{2}{|c|}{ Lost-foam } & \multicolumn{2}{|c|}{ Green sand } & \multicolumn{2}{|c|}{ Lost-foam } & \multicolumn{2}{|c|}{ Green sand } & \multicolumn{2}{|c|}{ Lost-foam } & \multicolumn{2}{|c|}{ Green sand } & \multicolumn{2}{|c|}{ Lost-foam } & \multicolumn{2}{|c|}{ Green sand } \\
\hline & $\begin{array}{l}T_{\mathrm{AL}} \\
\left({ }^{\circ} \mathrm{C}\right)\end{array}$ & $\begin{array}{l}t_{\mathrm{AL}} \\
(\mathbf{s})\end{array}$ & $\begin{array}{l}T_{\mathrm{AL}} \\
\left({ }^{\circ} \mathrm{C}\right)\end{array}$ & $\begin{array}{l}t_{\mathrm{AL}} \\
(\mathbf{s})\end{array}$ & $\begin{array}{l}T_{\mathrm{AC}} \\
\left({ }^{\circ} \mathrm{C}\right)\end{array}$ & $\begin{array}{l}t_{\mathrm{AC}} \\
(\mathbf{s})\end{array}$ & $\begin{array}{l}T_{\mathrm{AC}} \\
\left({ }^{\circ} \mathrm{C}\right)\end{array}$ & $\begin{array}{l}t_{\mathrm{AC}} \\
(\mathbf{s})\end{array}$ & $\begin{array}{l}T_{\text {ES }} \\
\left({ }^{\circ} \mathrm{C}\right)\end{array}$ & $\begin{array}{l}t_{\mathrm{ES}} \\
(\mathrm{s})\end{array}$ & $\begin{array}{l}T_{\mathrm{ES}} \\
\left({ }^{\circ} \mathrm{C}\right)\end{array}$ & $\begin{array}{l}t_{\mathrm{ES}} \\
(\mathrm{s})\end{array}$ & $\begin{array}{l}T_{\text {EN }} \\
\left({ }^{\circ} \mathrm{C}\right)\end{array}$ & $\begin{array}{l}t_{\mathrm{EN}} \\
(\mathrm{s})\end{array}$ & $\begin{array}{l}T_{\text {EN }} \\
\left({ }^{\circ} \mathrm{C}\right)\end{array}$ & $\begin{array}{l}t_{\mathrm{EN}} \\
(\mathrm{s})\end{array}$ \\
\hline 6 & 1211.9 & 604.2 & 1216.0 & 614.4 & 1206.9 & 710.4 & 1208.3 & 712.2 & 1149.1 & 1051.2 & 1152.3 & 997.6 & 1141.2 & 1841.9 & 1138.6 & 1555.1 \\
\hline 5 & 1210.1 & 578.4 & 1214.9 & 597.3 & 1202.3 & 665.1 & 1207.9 & 673.9 & 1148.2 & 1019.6 & 1151.9 & 979.7 & 1140.4 & 1813.4 & 1138.2 & 1502.1 \\
\hline 4 & 1209.1 & 551.6 & 1214.9 & 560.3 & 1199.7 & 619.8 & 1206.2 & 617.8 & 1147.7 & 990.1 & 1151.1 & 919.4 & 1139.9 & 1698.8 & 1137.3 & 1426.8 \\
\hline 3 & 1208.2 & 480.1 & 1212.9 & 496.2 & 1197.9 & 540.7 & 1202.5 & 545.6 & 1146.1 & 924.8 & 1150.2 & 871.3 & 1138.2 & 1597.2 & 1136.5 & 1350.7 \\
\hline 2 & 1200.4 & 458.1 & 1209.1 & 469.5 & 1195.0 & 493.7 & 1196.9 & 490.9 & 1144.9 & 788.1 & 1149.9 & 798.5 & 1137.1 & 1333.3 & 1136.2 & 1219.7 \\
\hline 1 & - & - & - & - & - & - & - & - & 1140.9 & 654.3 & 1147.4 & 723.4 & - & - & - & - \\
\hline
\end{tabular}

\subsection{Construction of DSC}

Based on the data presented in Table 4, where time $t$ is abscissa, the relative distance of the temperature measuring point to the casting surface is ordinate (surface is 0 , the center is 1 ), the dynamic solidification curves (DSC) of the lost-foam casting (solid line) and green sand mold casting (dotted line) under nonequilibrium solidification condition (Fig. 11a) and time domain diagrams of various phase regions of cross sections with a relative distance of 0.4 (Fig. 11b) are plotted. In addition, the double thermocouple Fourier analysis method ${ }^{[15]}$ was used to obtain the

(a)

(b)

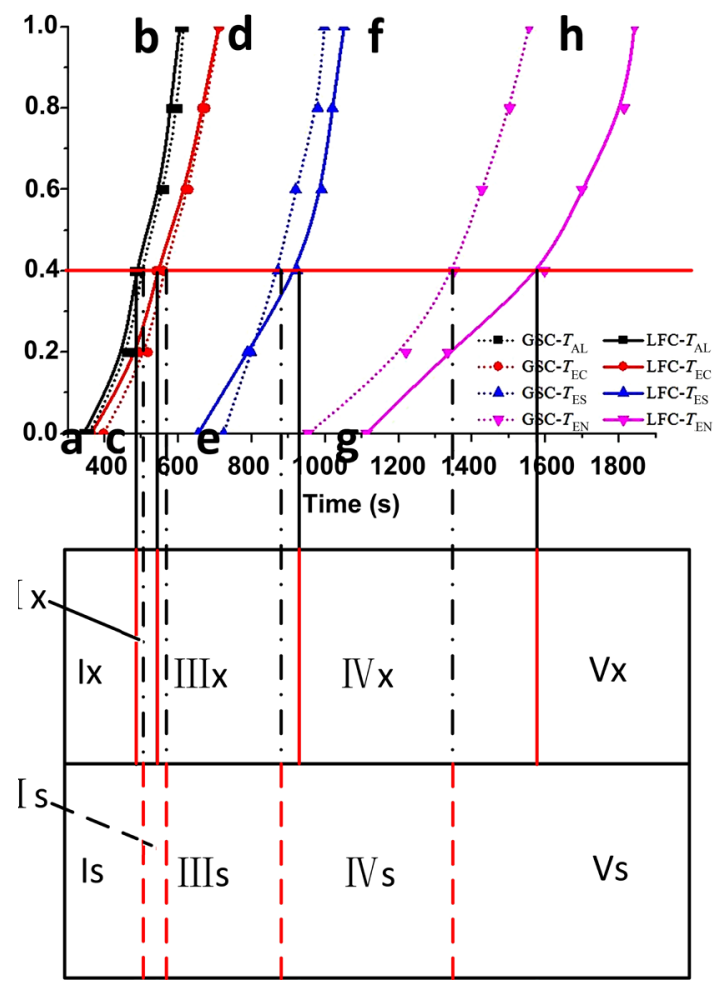

Fig. 11: Non-equilibrium DSC (a, upper) of hypoeutectic gray iron and time diagram (b, bottom) of various phase regions at cross section with a relative distance of 0.4 (Note: In Fig.11a (upper), $t_{\mathrm{AL}}, t_{\mathrm{AC}}$ and $t_{\mathrm{EN}}$ values are obtained by the extrapolation method. In Fig.11b (bottom), subscript $\mathrm{X}$ represents lost-foam casting, and $\mathrm{S}$ represents green sand casting.) solid fraction $f_{\mathrm{s}}$ of samples during solidification. Figure 12 shows the change curve of solid fraction $f_{\mathrm{s}}$ over time.

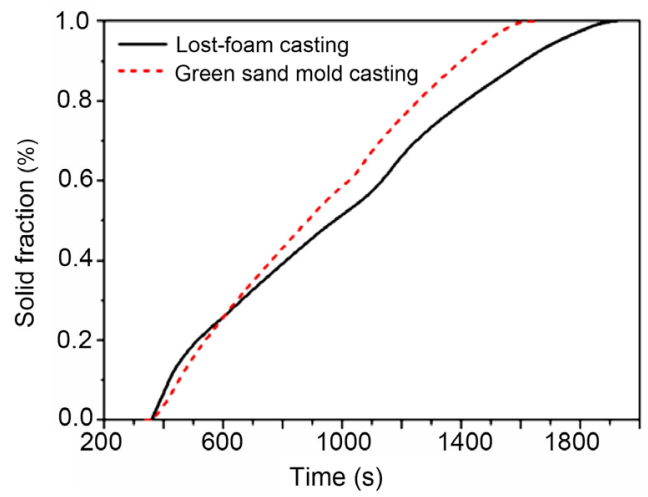

Fig. 12: Change of solid fraction $f_{\mathrm{s}}$ with time in solidification process of casting

\section{Analysis of macro-solidification process characteristics}

According to the curves (Figs. 11 and 12) that are established in terms of the overall characteristics of the non-equilibrium macroscopic solidification process of hypoeutectic gray iron casting, the boundary lines a-b and g-h divide the whole graph into three broad areas: liquid phase region, liquid-solid two phase region ( II $+\mathrm{III}+\mathrm{IV}$ ), and solid phase region $(\mathrm{V})$; while $\mathrm{c}-\mathrm{d}$ and e-f lines further divide the liquid-solid two phase region into three partitions: primary austenite precipitation zone II, primary austenite maturation growth zone III, and eutectic solidification zone IV. It can be seen from the dynamic solidification curve graph that there can only be two different areas at any moment during the macro solidification process of the hypoeutectic gray cast iron. The whole solidification process is composed of liquid phase $\rightarrow$ liquid phase + liquid-solid phases $\rightarrow$ liquid-solid two phases $\rightarrow$ liquid-solid two phases + solid phase $\rightarrow$ solid phase, where there is no coexistence region of liquid phase, liquidsolid phases, and solid phase. This is a typical physical model of two-region solidification. It suggests that the physical model of 
the two-region solidification exists not only in the macroscopic solidification process of the hypoeutectic gray iron castings with small cross-section size $(\Phi 30 \mathrm{~mm}){ }^{[6]}$, but also in the macro solidification process of the larger cross-section castings. It is a common phenomenon not related to the casting section size.

Compared with green sand casting, the macroscopic solidification process of lost-foam casting hypoeutectic gray iron under nonequilibrium solidification condition has the following characteristics:

(1) The early stage of the macroscopic solidification process is rapid. The liquid boundary line a-b has a greater slope. However, due to the vaporization and negative pressure in lost-foam casting, the chilling effect at the surface of casting is stronger, the instantaneous temperature of molten iron at the end of the filling is low, and Point a on the a-b line has an earlier start and a greater slope than green sand mold casting. With the $a-b$ line moved to the casting center, the two curves gradually converge at Point $\mathbf{b}$, that is, the center of casting.

(2) Zone II is narrower during the overall solidification range of hypoeutectic gray cast iron. The two lines c-d of lost-foam casting and green sand casting are very close (Fig. 11a), but zone II of the lost-foam casting is slightly larger than that of the green sand casting. Therefore, lost-foam casting is in a more favorable position than green sand casting in reducing the hypoeutectic gray cast iron shrinkage cavity, as well as the macro shrinkage porosity and mechanical burnt-on sand tendency ${ }^{[16]}$.

(3) Zone III is a large solidification area in the range of the solidification temperature (from $T_{\mathrm{AC}}$ to $T_{\mathrm{ES}}$ ), and the temperature gradient is not too large, so it constitutes a typical mushy solidification area. The variation of characteristics of the boundary line e-f in lost-foam casting is worth noticing. Due to foam vaporization and negative pressure, the effect on the solidification temperature field of lost-foam gradually weakened after the solidification process entered zone III. The effect of sand mold thermal performance gradually strengthened, so the slope of the boundary line e-f began to decrease and the intersecting phenomenon of the lost-foam casting and green sand mold casting curves appears. Therefore, the starting time (Point $\mathbf{e}$ ) of eutectic solidification in lost foam casting is earlier than that in green sand casting at the surface of casting, but the starting time (Point $\mathbf{f}$ ) of eutectic solidification is after the green sand casting at the center of casting, where the effect of sand mold thermal conductivity is stronger.

(4) After entering the eutectic solidification area, the effect of thermal conductivity of green sand casting on the temperature field becomes the leading control factor, and the solidification speed of the lost-foam casting slows down further. Therefore, at the end of the solidification, the slope of the boundary line g-h in lost-foam casting is further reduced and the whole boundary line falling behind the green sand casting is more obvious, and thus constitutes a larger mushy area. The DSC shows that under the same conditions, the total solidification time of lost-foam casting is greater than that of green sand casting.

\section{Conclusions}

(1) During the macro-solidification process of hypoeutectic gray cast iron, there can be only two different areas at any given moment. The physical model of two-region solidifications covers not only the macroscopic solidification process of the small crosssection ( $\Phi 30 \mathrm{~mm}$ ) castings of hypoeutectic gray cast iron, but also that of larger cross-section castings. It is a common phenomenon not related to the casting section size.

(2) The transformation rate of non-equilibrium solidification is larger than that of equilibrium solidification in hypoeutectic gray cast iron. The eutectic solidification region presents a typical mushy solidification mode. The results show that the eutectic solidification of hypoeutectic gray cast iron with layer-by-layer solidification derived from the classical DSC is not suitable for the non-equilibrium solidification process.

(3) Primary austenite precipitation zone of lost-foam casting is slightly larger than that of green sand casting. At the same time, the solid fraction of the dendrite coherency points in lost-foam casting is greater than that in the green sand casting. Therefore, from these two points, lost-foam casting is more preferable for reduction of shrinkage and mechanical burnt-in sand tendency of the eutectic gray cast iron.

(4) The solidification process (from the surface to center) at primary austenite growth area in the lost-foam cylinder sample lags behind that in the green sand casting. Therefore, the solidification tendency of lost-foam is greater and the solidification time is longer.

\section{References}

[1] Ruddle R W. The solidification of Castings. 2nd ed. London: Institute of Metals, 1957.

[2] Dunphy R P, Pellini W S. Solidification of gray iron in sand molds. Transactions of the American Foundrymen's Society, 1951, 59: 425.

[3] Flinn R A. Fundamentals of Metal Casting. Boston: AddisonWesley Publishing Company, 1963: 87-97.

[4] Ding Linpu, Lin Rui, Li Jiarong, et al. Effect of cooling condition on solidification characteristic of heavy ductile iron castings. Foundry, 1989(12) 19-22. (In Chinese)

[5] Feng Xiaoming, Zhang Zhengzhong, Li Dongzhi. The temperature field and DSC of medium manganese cast iron grinding balls. Journal of Shaanxi Institute of Technology, 1992 (1): 87-93. (In Chinese)

[6] Wu Xumin, Yu Xiaohua, Zhang Youling. Two-region crystal microphysical model in primary crystallization process of hypoeutectic cast iron. Foundry Technology, 2002, 23(4): 251253. (In Chinese)

[7] Svidró P, Diószegi A. On problems of volume change measurements in lamellar cast iron. International Journal of Cast Metals Research, 2014, 27(1): 26-37.

[8] Svidró P, Diószegi A. Determination of the columnar to equiaxed transition in hypoeutectic lamellar cast iron. ISIJ international, 2014, 54(2): 460-465.

[9] Chisamera M, Riposan I, Stan S, et al. Thermal analysis control of in-mould and ladle inoculated grey cast irons. China Foundry, 2009, 6(2): 145-151. 
[10] Dioszegi A, Svensson IL. On the problems of thermal analysis of solidification. Materials Science and Engineering A, 2005, 413414: 474-479.

[11] Backerud L, Chalmers B. Some aspects of dendritic growth in binary alloys-study of the aluminum-copper system. Trans Met Soc AIME, 1969, 245(2): 309-318.

[12] Ir G Henderieckx Gietech B V. Classification of foundries type of moulding. Germany: Gietech, 2011.

[13] Stefanescu D M. ASM Handbook, volume 15: Casting. 9th Edition, ASM International, USA, 1988.
[14] Stan S, Chisamera M, Riposan I, et al. Application of thermal analysis to monitor the quality of hypoeutectic cast irons during solidification in sand and metal moulds. Journal of Thermal Analysis and Calorimetry, 2011, 110(3): 1185-1192.

[15] Diószegi A, Hattel J. Inverse thermal analysis method to study solidification in cast iron. International Journal of Cast Metals Research, 2004, 17(5): 311-318.

[16] Diószegi A, Elmquist L, Orlenius J, et al. Defect Formation of Gray Iron Casting. International Journal of Metalcasting, 2009, $3(4): 49-58$. 